
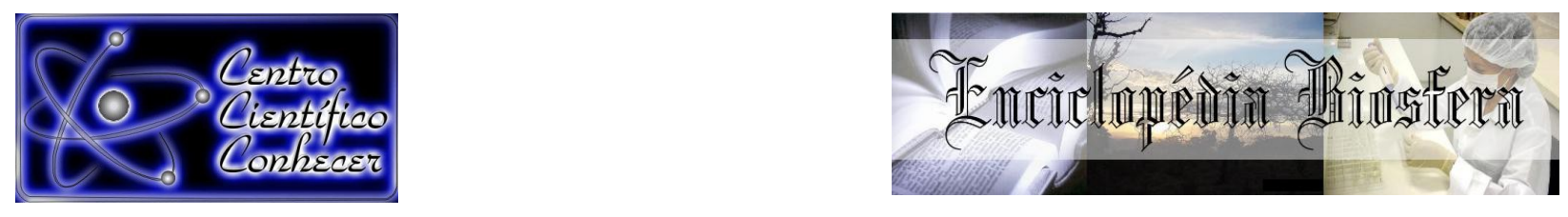

\title{
LEPTOSPIROSE EM PROPRIEDADE RURAL COM HISTÓRICO DE ABORTO EM VACAS LEITEIRAS NO MUNICÍPIO DE TRINDADE, ESTADO DE GOIÁS - RELATO DE CASO
}

\section{Deborah Cristina Fogaça ${ }^{1}$; Helena Tavares Dutra²; Cairo Henrique Sousa de Oliveira ${ }^{3}$}

1 - Residência em Sanidade Animal - Universidade Federal de Goiás, Goiânia - Goiás.Email: deborahmvet@gmail.com

2 - Residência em Clínica e Cirurgia de Grandes Animais - Universidade Federal de Goiás, Goiânia - Goiás.

3 - Professor Adjunto, Doenças Infecciosas dos Animais - Universidade Federal de Goiás, Goiânia - Goiás.

Recebido em: em: 06/04/2018 - Aprovado em: 10/06/2018 - Publicado em: 20/06/2018 DOI: 10.18677/EnciBio_2018A57

\begin{abstract}
RESUMO
A leptospirose é uma zoonose de distribuição mundial decorrente da infecção por bactérias patogênicas do gênero Leptospira, a qual ocorre principalmente pelo contato direto com a urina de animais infectados. A espécie bovina é considerada responsável pela manutenção do sorovar Hardjo, o que pode estar associado à infecção persistente do trato reprodutivo, aborto e infertilidade. O objetivo do trabalho é relatar a ocorrência de cinco abortos e o nascimento de dois bezerros fracos em um lote de quarenta vacas, devido à infecção por Leptospira spp. em uma propriedade rural, localizada no município de Trindade. Foram coletadas amostras de sangue para a realização de exames sorológicos para leptospirose, toxoplasmose, neosporose, diarreia viral bovina, rinotraqueíte infecciosa bovina e brucelose, a fim de investigar a causa da ocorrência dos abortos e de outros problemas reprodutivos observados na propriedade. Dos oito animais avaliados, quatro apresentaram titulação contra os sorovares Pomona, Hardjo e Icterohaemorrhagiae pela análise de soroaglutinação microscópica para o diagnóstico de leptospirose, seis apresentaram anticorpos contra o Herpesvírus bovino tipo 1 e três animais foram reagentes ao parasito Neospora caninum. Nenhum dos animais foi positivo para a diarreia viral bovina, brucelose e toxoplasmose. Associado a observação dos fatores de risco, dados epidemiológicos e técnicas de manejo, os resultados das análises laboratoriais conduziram à conclusão diagnóstica de leptospirose, não sendo descartada a possibilidade da ocorrência concomitante de outras doenças de importância reprodutiva na espécie bovina.
\end{abstract}

PALAVRAS-CHAVE: Aborto, bovinos, doenças infecciosas, zoonose.

\section{LEPTOSPIROSIS IN DAIRY COWS WITH ABORTION OCCURRENCE AND OTHER REPRODUCTIVE PROBLEMS IN THE STATE OF GOIÁS - CASE REPORT}

ABSTRACT

Leptospirosis is a zoonosis of worldwide distribution due to infection with pathogenic bacteria of the genus Leptospira, which occurs mainly by direct contact with the urine ENCICLOPÉDIA BIOSFERA, Centro Científico Conhecer - Goiânia, v.15 n.27; p. 108 2018 
of infected animals. The bovine species is considered responsible for the maintenance of the serovar Hardjo, which may be associated with persistent infection of the reproductive tract, abortion and infertility. The objective of the study is to report the occurrence of five abortions and the birth of two weak calves in a batch of forty cows due to infection with Leptospira spp. in a rural property, located in the district of Trindade. Blood samples were collected for serological tests for leptospirosis, toxoplasmosis, neosporosis, bovine viral diarrhea, infectious bovine rhinotracheitis and brucellosis, in order to investigate the cause of abortions and other reproductive problems observed on the farm. Of the eight animals evaluated, four presented titration against the Pomona, Hardjo and Icterohaemorrhagiae serovars by microscopic serum agglutination analysis for the diagnosis of leptospirosis, six had antibodies against bovine herpesvirus type 1 and three animals were reactive to the parasite Neospora caninum. None of the animals were positive for bovine viral diarrhea, brucellosis and toxoplasmosis. Associated with the observation of risk factors, epidemiological data and management techniques, the results of the laboratory tests led to the diagnostic conclusion of leptospirosis, and the possibility of the concomitant occurrence of other diseases of reproductive importance in the bovine species was not ruled out.

KEYWORDS: Abortion, cattle, infectious diseases, zoonosis.

\section{INTRODUÇÃO}

A leptospirose é uma antropozoonose bacteriana de alta prevalência e de distribuição mundial, diagnosticada em países de clima tropical, principalmente nos períodos chuvosos (PAIXÃO et al., 2016). É causada por bactérias do gênero Leptospira, constituído pelas espécies L. interrogans e L. biflexa (WHO, 1967).

A disseminação de Leptospira spp. nas criações de bovinos ocorre pelo contato com secreções, especialmente a urina, de animais doentes ou portadores assintomáticos, os quais eliminam a bactéria e contribuem para a manutenção da doença no rebanho (COELHO et al., 2014). A imunização é indispensável no controle da leptospirose, mas isoladamente não é suficiente na prevenção da infecção. A prevenção da leptospirose baseia-se na adoção de medidas sanitárias gerais. A vacinação deve ser realizada, mas é necessário o conhecimento epidemiológico dos sorovares prevalentes na região (PAIXÃO et al., 2016; JORGE et al., 2017; YADETA et al., 2016).

A infecção leptospírica é uma das principais causas de falha reprodutiva em bovinos, causando prejuízos econômicos significativos relacionados a abortos, natimortos, nascimento de bezerros fracos e diminuição da produção. Foi estimado que $30 \%$ das vacas do rebanho brasileiro apresentam algum tipo de problema reprodutivo, frequentemente resultante de doenças infecciosas (LILEMBAUM et al., 2014).

A avaliação da prevalência sorológica da leptospirose em um rebanho leiteiro da cidade de Goiânia, estado de Goiás, detectou resposta aos sorovares Wolffi e Icterohaemorrhagiae como as mais prevalentes (36,10\% e $20,50 \%$ respectivamente) (JULIANO et al., 2000). Isso demonstra que a leptospirose é endêmica nessa microrregião e, por isso, é essencial conhecer sua epidemiologia em cada localidade, além de identificar os sorovares mais frequentes (JULIANO et al., 2000).

Os sorovares Hardjo e Pomona são os de maior relevância na ocorrência de abortos em vacas, embora outros sorovares, como por exemplo Icterohaemorrhagiae, também possam causar problemas reprodutivos. O aborto é a manifestação clínica da leptospirose crônica, sendo muitas vezes o único sinal 
observado no rebanho (ANDERSON, 2007) ou acompanhado por falha reprodutiva, nascimento de bezerros fracos ou natimortos (LOUREIRO et al., 2013).

O objetivo do trabalho é relatar a ocorrência de um surto de aborto devido a leptospirose em vacas leiteiras de uma propriedade rural, localizada no estado de Goiás.

\section{RELATO DE CASO}

No dia 26 de setembro de 2017, foi realizada uma visita técnica para avaliar a causa de abortos em uma propriedade rural localizada no município de Trindade, estado de Goiás. A propriedade possuía um rebanho de 130 bovinos da raça Gir para a produção de leite pelo sistema de pastejo rotacionado. A rotação era realizada em quatorze piquetes de pastagem. No período seco do ano os animais eram submetidos a suplementação com silagem de milho e farelo de soja. Também era administrado sal mineral com ureia a $25 \%$ para todos os lotes.

A ordenha era mecanizada e as vacas separadas em lotes de pré-parto e pósparto. Para o manejo reprodutivo era realizada a técnica de inseminação artificial em tempo fixo (IATF), utilizando sêmen de diversos touros, coletados em centrais de reprodução e diretamente em fazendas. Os animais que não emprenhavam na IATF eram colocados com um touro de repasse.

Os animais eram vacinados contra a febre aftosa, brucelose, raiva, clostridioses, rinotraqueíte infecciosa bovina (IBR) e diarreia viral bovina (BVD). Foi relatada ausência de vacinação para a leptospirose. A vermifugação dos animais era feita de duas a seis vezes por ano. Havia histórico de baixa frequência de compra de animais, os quais eram submetidos a um período de quarentena antes da introdução no rebanho.

A fonte de água dos animais era proveniente de um poço semi-artesiano, ofertada em cochos de concreto e foi observada presença de uma lagoa em um dos piquetes (Figura 1A e 1B). As vacas que estavam paridas e em lactação ficavam nos piquetes em que a água era proveniente do poço (Figura 1A). As fêmeas que estavam prenhes e secas ficavam no piquete onde a fonte de água era a lagoa (Figura 1B). Os bovinos tinham contato com outras espécies animais, sendo um cão e três gatos. Não foi relatado e nem observada presença de roedores na propriedade.

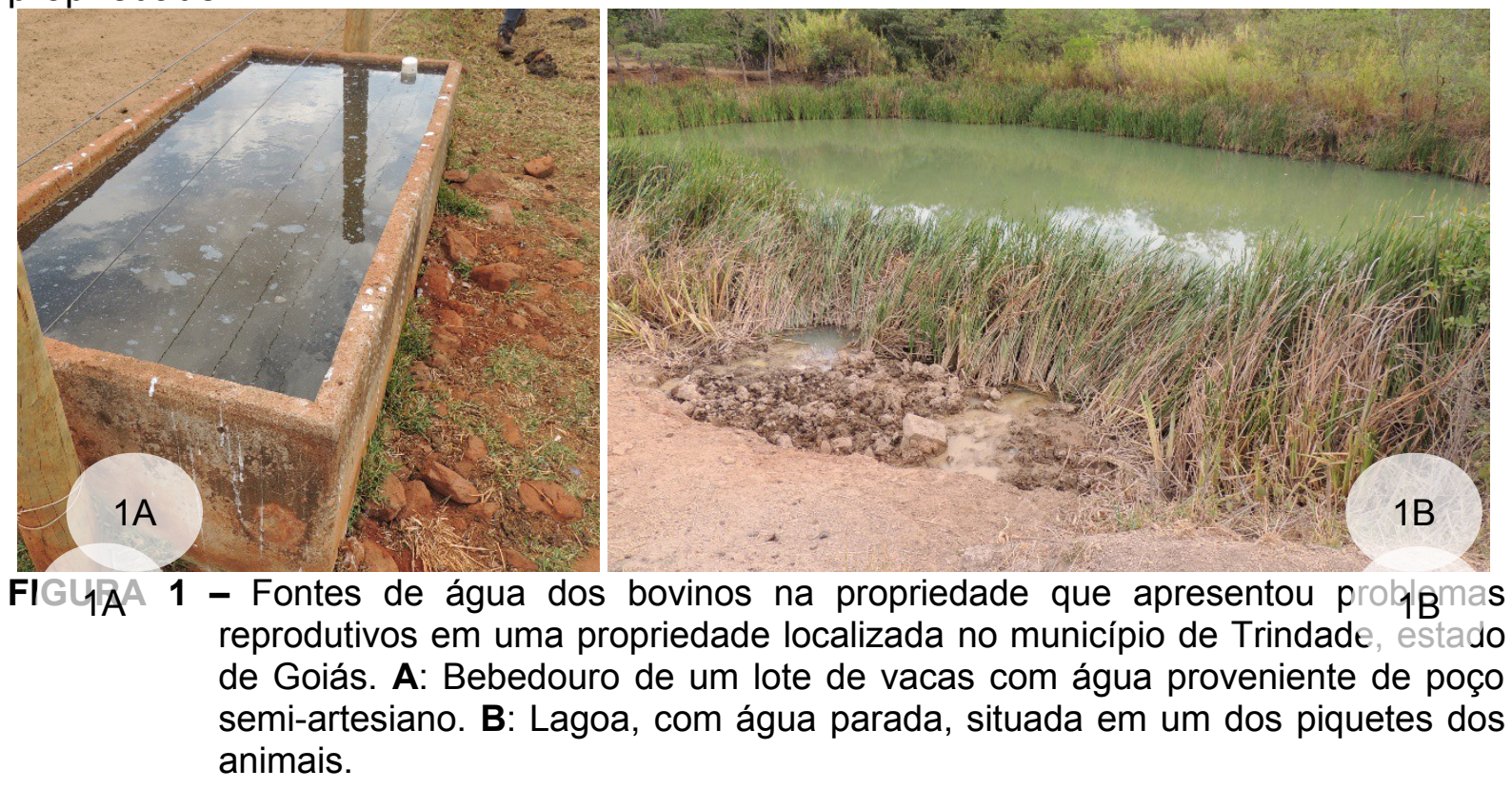


Fonte: Acervo pessoal.

O motivo da visita técnica foi a ocorrência de cinco abortos e o nascimento de dois bezerros fracos em um lote de quarenta vacas (Figura 2), o qual era formado por vacas, da raça Gir, de diferentes faixas etárias. Os abortos ocorriam geralmente quarenta dias antes da data prevista para o parto (Quadro 1). Foi também relatada rara ocorrência de retenção de placenta e absorção embrionária com repetição de cio.

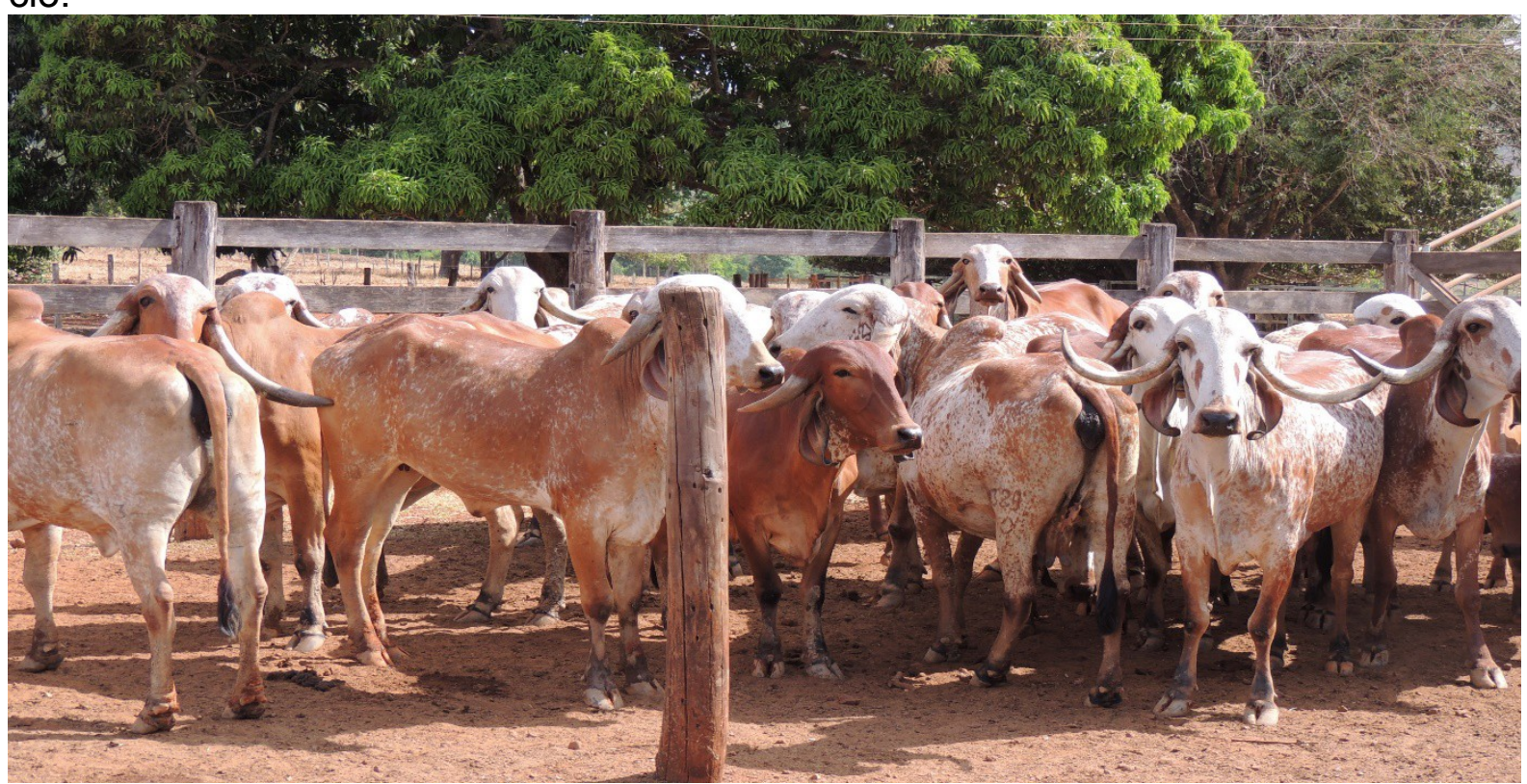

FIGURA 2 - Lote de vacas em gestação ou em manejo reprodutivo, que apresentaram casos de aborto no segundo trimestre gestacional em uma propriedade localizada no município de Trindade, estado de Goiás.

Fonte: Acervo pessoal.

QUADRO 1 - Animais do lote de vacas da raça Gir que apresentaram aborto e/ou outros problemas reprodutivos, origem do sêmen utilizado em cada vaca e intervalo de antecipação do parto.

\begin{tabular}{|c|c|c|c|}
\hline Identificação & $\begin{array}{c}\text { Problema } \\
\text { reprodutivo }\end{array}$ & Origem do sêmen & $\begin{array}{c}\text { Intervalo (dias) de } \\
\text { antecipação do } \\
\text { parto }\end{array}$ \\
\hline 1 & $\begin{array}{c}\text { Nascimento de } \\
\text { bezerro fraco - } \\
\text { morte após 48 } \mathrm{h}\end{array}$ & Touro A & 16 \\
\hline 2 & Aborto & Touro A & 68 \\
\hline 3 & Aborto & Touro B & 60 \\
\hline 4 & $\begin{array}{c}\text { Aborto e nascimento } \\
\text { de bezerro fraco }\end{array}$ & Touro C & 18 \\
\hline 5 & $\begin{array}{c}\text { Sem problemas } \\
\text { reprodutivos } \\
\text { Aborto }\end{array}$ & Desconhecida & - \\
\hline 6 & Touro D & 15 \\
\hline
\end{tabular}

ENCICLOPÉDIA BIOSFERA, Centro Científico Conhecer - Goiânia, v.15 n.27; p. 1112018 


\begin{tabular}{|l|c|c|c|}
\hline 7 & $\begin{array}{c}\text { Nascimento de } \\
\text { bezerro fraco e } \\
\text { vaginite }\end{array}$ & Touro E & 7 \\
\hline
\end{tabular}

Anterior à visita técnica, foi realizada coleta de sangue para obtenção de soro sanguíneo e posterior realização de exames de sorologia para leptospirose e brucelose de três vacas que abortaram e três vacas que não tinham histórico de aborto, mas pertenciam ao mesmo lote. A coleta havia sido realizada pelo proprietário um dia antes da visita técnica. Quatro vacas apresentaram títulos de anticorpos contra Leptospira interrogans sorovar Pomona; duas vacas foram reagentes para o sorovar Wolffi; cinco vacas demonstraram reação ao sorovar Tarassovi e cinco vacas apresentaram titulação contra o sorovar Patoc. Os resultados apresentaram variação de titulação de 100 a 400.

No dia da visita técnica, foram coletadas amostras de sangue (via veia caudal) de: três vacas com histórico de aborto (2, 3 e 6); três vacas com outros problemas reprodutivos (1, 4 e 7 ), uma delas com sinais de vaginite (7); uma vaca que não havia abortado, mas apresentou apatia e diarreia (5) e um bezerro nascido fraco (8), filho da vaca 7 , para a realização de exames diagnósticos das doenças reprodutivas de maior relevância em bovinos.

As amostras de sangue foram centrifugadas no Laboratório de Patologia Clínica (LPC/HV/EVZ/UFG) para a separação do soro sanguíneo. As amostras de soro sanguíneo foram conservadas congeladas e então enviadas ao Instituto Biológico de São Paulo (IB) para a realização de exames sorológicos para leptospirose, toxoplasmose, neosporose, diarreia viral bovina (BVD) e rinotraqueíte infecciosa bovina (IBR). A investigação diagnóstica foi baseada nas características clínicas e epidemiológicas observadas e no conhecimento das principais enfermidades relacionadas a problemas reprodutivos na espécie bovina.

A técnica utilizada para a análise sorológica da leptospirose foi a soroaglutinação microscópica (SAM). Os sorovares empregados foram: Icterohaemorrhagiae (ICT), Canicola, Pomona (POM), Grippotyphosa, Wolffi, Hardjo (HAR), Australis, Autumnalis, Bataviae, Bratislava, Butembo, Castellonis, Copenhageni, Cynopteri, Hebdomadis, Javanica, Panama, Pyrogenes, Shermani, Tarassovi, Whitcombi, Sentot. O valor de referência considerado é igual ou superior a 100 para animais reagentes.

Para a detecção de anticorpos contra o BoHV-1 e o BVDV foi realizado a técnica de vírus-neutralização (com títulos de anticorpos expressos em log10). Foram utilizadas células MDBK e dose viral recomendada de 2000 DICT50/MI. Para o BoHV-1 foram considerados reagentes os valores maiores ou iguais a 2 e para o BVDV os valores iguais ou superiores a 10 foram considerados como reagentes.

A técnica de imunofluorescência indireta foi utilizada para a detecção de anticorpos contra os parasitos Neospora caninum e Toxoplasma gondii. Os valores considerados como não reagentes à presença de anticorpos contra $N$. caninum são inferiores a 200 e devem ser menores que 40 em relação ao parasito $T$. gondii. Para o diagnóstico sorológico da brucelose bovina, realizou-se o teste do antígeno acidificado tamponado, considerado como um teste de triagem de caráter qualitativo.

\section{RESULTADOS}

Durante a visita técnica, verificou-se que os animais apresentavam escore corporal bom e nenhum animal apresentava sinais de enfermidade ao exame clínico. As amostras de soro sanguíneo processadas no Instituto Biológico de São Paulo (IB) 
demonstraram sorologia positiva para infecção leptospírica, BoHV-1 e neosporose (Quadro 2). A vaca 4 apresentou anticorpos contra os sorovares Pomona (400) e Hardjo (200); a vaca 5 foi reagente contra os sorovares Harjo (400) e Icterohaemorrhagiae (100); a vaca 6 apresentou títulos de anticorpos contra os sorovares Pomona (100), Harjo (800) e Icterohaemorrhagiae (100) e a vaca 7 foi reagente contra os sorovares Pomona (100) e Harjo (200). Os animais 1, 3, 4, 6, 7 e 8 apresentaram anticorpos contra o BoHV-1 (títulos de 4, 4, 512, 512, 512 e 8, respectivamente). Três animais foram reagentes ao parasito Neospora caninum, com títulos de 200 (vacas 3, 4 e 6). Nenhum animal apresentou anticorpos contra o BVDV e Toxoplasma gondii. Todos os animais foram negativos para o teste do antígeno acidificado tamponado para diagnóstico da brucelose bovina.

QUADRO 2 - Resultados do teste de soroaglutinação microscópica (SAM) para detecção de anticorpos anti-Leptospira, dos exames de virusneutralização para detecção de anticorpos contra o Herpesvirus bovino tipo 1 (BoHV-1) e vírus da diarreia viral bovina (BVDV), e análises de imunofluorescência indireta para a detecção de anticorpos contra os parasitos Toxoplasma gondii e Neospora caninum e teste do antígeno acidificado tamponado (AAT) para diagnóstico da brucelose bovina.

\begin{tabular}{|c|c|c|c|c|c|c|c|c|}
\hline \multicolumn{9}{|c|}{ RESULTADOS } \\
\hline Animal & \multicolumn{3}{|c|}{ Leptospirose } & BoHV-1 & Neospor & BVDV & Toxoplasma & $\overline{\mathrm{AAT}}$ \\
\hline & \multicolumn{3}{|c|}{ Sorovares } & & & & & \\
\hline & POM & HAR & ICT & & & & & \\
\hline 1 & NR & NR & NR & 4 & - & - & - & - \\
\hline 2 & NR & NR & NR & - & - & - & - & - \\
\hline 3 & NR & NR & NR & 4 & 200 & - & - & - \\
\hline 4 & 400 & 200 & - & 512 & 200 & - & - & - \\
\hline 5 & - & 400 & 100 & - & - & - & - & - \\
\hline 6 & 100 & 800 & 100 & 512 & 200 & - & - & - \\
\hline 7 & 100 & 200 & - & 512 & - & - & - & - \\
\hline 8 & \multicolumn{3}{|c|}{ NR } & 8 & - & - & - & - \\
\hline
\end{tabular}

NR=Não Realizado

- Negativo ou não reagente

De acordo com a análise dos resultados e dados epidemiológicos da propriedade, a conclusão diagnóstica dos casos de aborto foi leptospirose bovina. Foi recomendada aplicação de uma dose de $25 \mathrm{mg} / \mathrm{kg}$ de estreptomicina (Estreptomax ${ }^{\circledR}$, Ourofino Saúde Animal, Cravinhos, SP, Brasil) em cada uma das vacas do lote que apresentaram problema reprodutivo. Ademais, sugeriu-se a vacinação contra leptospirose em todos os animais, com recomendação da realização de uma dose adicional após trinta dias e reforço vacinal a cada seis meses. 


\section{DISCUSSÃO}

A coleta de informações relacionadas aos problemas reprodutivos no rebanho é uma ferramenta importante para o diagnóstico da causa de abortos em bovinos. Algumas informações úteis são: a estimativa da taxa de abortos, duração da ocorrência dos abortos e o tempo de gestação em que ocorrem os mesmos, presença de retenção de placenta, histórico vacinal, condição dos fetos abortados (autólise) e se há ocorrência dos abortos em novilhas, vacas ou ambos (ANDERSON, 2007). De acordo com o observado na propriedade atendida, a taxa de aborto no lote foi de $12,5 \%(5 / 40)$ e não era realizada vacinação contra leptospirose. Os abortos ocorriam no final da gestação e havia nascimento de bezerros fracos, os quais geralmente vinham a óbito em até 48 horas após o parto.

Nas amostras coletadas durante a visita técnica para o diagnóstico sorológico da leptospirose, foram detectados anticorpos contra os sorovares Hardjo, Pomona e Icterohaemorrhagiae, com titulações variando de 100 a 800. Devido à ausência de vacinação contra a leptospirose, pode-se inferir que os títulos de anticorpos detectados eram referentes à infecção natural (MINEIRO, 2007).

A espécie bovina é o hospedeiro de manutenção do sorovar Hardjo, mas outros sorovares podem também estar relacionados à ocorrência de abortos (ANDERSON, 2007; OLIVEIRA et al., 2013; BALAMURUGAN et al., 2018; MARQUES et al., 2010). A resposta sorológica ao sorovar Hardjo na propriedade indica a presença dos mecanismos de transmissão de bovino a bovino, atuando como reservatórios responsáveis pela manutenção da infecção no rebanho (FERREIRA et al., 2017).

A identificação dos sorovares Harjo e Pomona indica que os bovinos da propriedade avaliada apresentaram resposta imunológica ativa à leptospirose. A infecção pelo sorovar Hardjo resulta em problemas reprodutivos e interfere na função do corpo lúteo, reduzindo assim os níveis de progesterona; já o sorovar Pomona apresenta alta patogenicidade e pode causar icterícia e abortos em bovinos (PAIXÃO et al., 2016), o que corrobora com as manifestações clínicas observadas de aborto e outros problemas de fertilidade.

Além dos abortamentos, foi relatada ocorrência rara de retenção de placenta, o que geralmente é associado à infecção pelos sorovares Pomona e Hardjo (FERREIRA et al., 2017). Apesar do relato da ausência de contato com suínos, os quais são os hospedeiros de manutenção do sorovar Pomona, este sorovar normalmente circula nas criações de bovinos, podendo auxiliar na manutenção da infecção no rebanho (FERREIRA et al., 2017).

A infecção pelo sorovar Icterohaemorrhagiae está relacionada à presença de roedores e tem grande importância para a saúde pública pelo fato de ser o principal sorovar infectante em seres humanos (FERREIRA et al., 2017). Apesar do relato da ausência de roedores na propriedade, há probabilidade da contaminação da fonte de água fornecida aos bovinos pela urina desses animais, uma vez que o alimento estocado em propriedades rurais é um dos principais atrativos à presença de roedores.

O aborto geralmente ocorre de um a três meses após o início da infecção pelo sorovar Hardjo e de uma a seis semanas depois da infecção inicial pelo sorovar Pomona. A infecção por $L$. hardjo está associada à ocorrência de infertilidade, abortos a partir do quarto mês de gestação e nascimento de bezerros fracos. Os abortos decorrentes da infecção por $L$. pomona comumente ocorrem no último 
trimestre gestacional (ANDERSON, 2007; PARTHIBAN et al., 2015), assim como os abortos que ocorreram na propriedade.

A realização de sorologia materna pelo teste de SAM é importante para o diagnóstico da leptospirose, porém deve-se distinguir os títulos resultantes de vacinação, exposição prévia e infecção recente (ANDERSON, 2007). No caso avaliado, não havia histórico de vacinação e foi observada presença de alguns fatores de risco, como, por exemplo, a lagoa que servia como fonte de água para um dos lotes, justamente ao lote de animais prenhes e não lactantes. Este fator de risco é determinante para ocorrência da leptospirose, uma vez que uma das formas de transmissão é a penetração da bactéria na pele a partir do contato com fontes de água contaminada ou áreas alagadiças (COELHO et al., 2014).

Dentre os fatores de risco para infecção leptospírica, animais que têm acesso à água de rios ou lagoas apresentam maiores chances de serem soropositivos pela técnica de SAM. Bovinos com infecção crônica contribuem para a manutenção e disseminação da leptospirose no rebanho, em associação às condições climáticas e ambientais, as quais favorecem a permanência da bactéria no ambiente por longos períodos (FAVERO et al., 2017). As vacas do lote que apresentou problemas reprodutivos tinham acesso a água de uma lagoa $e$, por se tratar de uma propriedade leiteira, há maior possibilidade da presença de portadores crônicos da doença no rebanho, uma vez que esses animais permanecem na propriedade por longos períodos, em comparação ao gado de corte.

Uma alternativa eficaz para a prevenção e controle da leptospirose em bovinos é o uso de vacinas elaboradas com o sorovar específico prevalente na propriedade ou região (ARAÚJO et al., 2005). A análise sorológica realizada demonstrou a presença de títulos contra os sorovares Pomona, Hardjo e Icterohaemorrhagiae. A vacina contendo os sorovares detectados está disponível no Brasil e foi indicada para o controle da enfermidade.

A estreptomicina foi um dos primeiros antibióticos a serem utilizados para a terapia antimicrobiana contra a leptospirose e ainda é considerada o antibiótico de primeira escolha (GIRIO et al., 2005), sendo eficaz no controle da leptospiremia e leptospiúria (KLAASEN; ADLER, 2015). Dessa forma, foi recomendado tratamento dos animais infectados com sulfato de estreptomicina na dosagem única de 25 $\mathrm{mg} / \mathrm{kg}$ (CAVAZINI et al., 2008), aliada à vacinação de todo o rebanho.

A rinotraqueíte infecciosa bovina (IBR) também é uma doença infecciosa que pode levar à ocorrência de abortos, geralmente entre o quarto e oitavo mês de gestação e a infecção pode resultar em morte embrionária precoce (PARTHIBAN et al., 2015), o que não condiz com as condições clínicas observadas na propriedade.

Os neonatos infectados pelo BoHV-1 podem desenvolver sinais de infecção sistêmica, salivação excessiva, diarreia e lesões por todo o trato gastrointestinal. A morte pode ocorrer em até cinco dias (MENEGAS et al., 2013). De acordo com o relato, os fetos abortados não apresentavam malformações e os bezerros que nasciam fracos não demonstraram sinais clínicos sugestivos de infecção pelo BoHV1. Em geral, o óbito ocorria em até no máximo 48 horas após o parto.

Os animais 1, 3, 4, 6, 7 e 8 foram reagentes no exame de vírus-neutralização para detecção de anticorpos contra o BoHV-1, com variação de títulos entre 4 e 512 . Foi relatada implementação da vacinação contra a IBR e BVDV na propriedade há dois anos. Portanto, a positividade para IBR pode estar relacionada à detecção de títulos vacinais.

A infecção pelo protozoário Neospora caninum frequentemente resulta em abortos durante o segundo trimestre gestacional, mumificação fetal ou nascimento 
de bezerros com sinais de acometimento do sistema nervoso central. Os fetos abortados são autolisados e há um acúmulo de fluido serossanguinolento nas cavidades corporais (ANDERSON, 2007), o que não foi observado ou relatado na propriedade estudada.

A quantidade de anticorpos a ser considerada como diagnóstico definitivo da neosporose ainda não foi estabelecido em bovinos, devido à dificuldade de interpretação da análise sorológica em animais cronicamente infectados e à viabilidade do soro de vacas não infectadas. Além disso, o ponto de corte pode ser afetado por fatores com a idade do animal e seleção de sensibilidade e especificidade solicitada para uma aplicabilidade específica (DUBEY, 2003). Dessa forma, apesar da positividade verificada em três animais (3, 4 e 6), não se pode afirmar que os abortos tenham ocorrido em consequência da neosporose, aliado ao fato de que o título encontrado (200) é considerado baixo e corresponde ao ponto de corte do teste.

O Vírus da diarreia viral bovina (BVDV) é relacionado à ocorrência de abortos durante o primeiro trimestre de gestação, comumente associado à reabsorção fetal, malformações fetais, mumificação e expulsão (NILNONT et al., 2016), e estes aspectos diferem do que foi avaliado na propriedade. Apesar das principais características comuns à infecção pelo BVDV não terem sido observadas, foi solicitada análise sorológica com o objetivo de estabelecer um diagnóstico diferencial amplo. Todos os animais foram negativos à presença de anticorpos antiBVDV.

Apesar da proximidade taxonômica entre os parasitos N.caninum e Toxoplasma gondii, a toxoplasmose não é considerada uma causa importante de problemas reprodutivos em bovinos, principalmente pela presença concomitante de outros agentes infecciosos (SILVA et al., 2015; SANTOS et al., 2009; OGAWA et al., 2005). Devido à possibilidade da ocorrência dessa zoonose na espécie bovina e ao relato do contato do rebanho com felinos, foi solicitada análise de imunofluorescência indireta para a detecção de anticorpos contra T. gondii. Porém, nenhum animal foi reagente nesta análise sorológica.

A brucelose é uma das principais zoonoses associadas à ocorrência de problemas reprodutivos em bovinos. Nos animais infectados pela Brucella abortus, os principais sinais clínicos observados são o nascimento de bezerros fracos, natimortos (PAL et al., 2017) e aborto, que ocorre mais comumente entre o sexto e nono mês de gestação (BARKALLAH et al., 2014). Em virtude da semelhança dessas características clínicas, foi realizado o teste do antígeno acidificado tamponado para diagnóstico da brucelose bovina e todos os animais foram negativos.

Diante da avaliação do caso, foi recomendada adoção de medidas higiênicosanitárias e de prevenção, como por exemplo a retirada dos animais do local em que a água fornecida era proveniente da lagoa e a proteção do local de armazenamento do alimento destinado aos bovinos. Além disso, orientou-se a realização do tratamento dos animais infectados e a vacinação de todos os lotes, com a finalidade de reduzir a disseminação do agente e diminuir os prejuízos econômicos decorrentes da infecção leptospírica no rebanho. Contudo, é importante salientar que a vacinação e o tratamento não impendem a infecção por outros sorovares, sendo assim indispensável a manutenção das medidas de controle e prevenção recomendadas e reavaliação sorológica do rebanho.

\section{CONCLUSÃO}


A associação dos dados epidemiológicos e características clínicas observadas na propriedade estudada possibilitou a confirmação do diagnóstico de leptospirose como causa de aborto em vacas leiteiras no município de Trindade. $O$ estudo do caso revelou a importância do diagnóstico diferencial das causas de problemas reprodutivos em bovinos, uma vez que a etiologia multifatorial é frequente nessas situações. O conhecimento da etiologia das doenças infecciosas auxilia na condução de medidas preventivas, técnicas adequadas de manejo e tratamento dos animais infectados, o que minimiza os riscos de disseminação do patógeno e reduz os prejuízos provocados pela infecção de animais suscetíveis.

\section{REFERÊNCIAS}

ANDERSON, M.L. Infectious causes of bovine abortion during mid- to late-gestation. Theriogenology, 68 (2007) 474-486. Disponível em: < http://dx.doi.org/10.1016/j.theriogenology.2007.04.001>. Doi: 10.1016/j.theriogenology.2007.04.001.

ARAÚJO, V.E.M.; MOREIRA, E.C.; NAVEDA, L.A.B.; SILVA, J.A.; CONTRERAS, R.L. Frequência de aglutininas anti-Leptospira interrogans em soros sanguíneos de bovinos, em Minas Gerais, de 1980 a 2002. Arquivo Brasileiro de Medicina Veterinária e Zootecnia. v.57 no.4 Belo Horizonte Ag. 2005. Disponível em: <http://dx.doi.org/10.1590/S0102-09352005000400002>. Doi: 10.1590/S010209352005000400002 . ISSN 1678-4162.

BALAMURUGAN V.; ALAMURI, A.; BHARATHKUMAR, K.; PATIL, S.S.; GOVINDARAJ, G.N.; NAGALINGAM, M.; KRISHNAMOORTHY, P.; RAHMAN, H.; SHOME, B.R. Prevalence of Leptospira serogroup-specific antibodies in cattle associated with reproductive problems in endemic states of India. Tropical Animal Health and Production (2018). Disponível em: <https://doi.org/10.1007/s11250-0181540-8>. Doi: 10.1007/s11250-018-1540-8.

BARKALLAH, M.; GHARBI, Y.; HASSENA, A.B.; SLIMA, A.B.; MALLEK, Z.; GAUTIER, M.; GREUB, G.; GDOURA, R.; FENDRI, I. Survey of infectious etiologies of bovine abortion during mid- to late gestation in dairy herds. Plos One (2014). Vol. 9, issue 3. Disponível em: <https://doi.org/10.1371/journal.pone.0091549>. Doi: 10.1371/journal.pone.0091549.

CAVAZINI, N.C.; SALDANHA, G.B.; SILVA, A.S.; FERNANDES, M.B.; BADKE, M.R.T.; PIVETA, C.G. Eficiência reprodutiva de vacas com leptospirose após tratamento com sulfato de estreptomicina. Revista da Faculdade de Zootecnia, Veterinária e Agronomia. Uruguaiana, v.15, n.1, p. 152-159. 2008. Disponível em: <http://revistaseletronicas.pucrs.br/ojs/index.php/fzva/article/view/3711>.

COELHO, E.L.M.; CHAVES, N.P.; SÁ, J.C.; MELO, S.A.; SILVA, A.L.A. Prevalência de leptospirose em fêmeas bovinas abatidas em frigoríficos no município de São Luís, MA. Revista Brasileira de Medicina Veterinária, 36(2):111-115, abr/jun 2014. Disponível em: <http://www.rbmv.com.br/pdf_artigos/10-12-2014_1605RBMV022.pdf> 
DUBEY, J.P. Review of Neospora caninum and neosporosis in animals. The Korean Journal of Parasitology. Vol. 41, No. 1. 1-16, March 2003. Disponível em: <http://dx.doi.org/10.3347/kjp.2003.41.1.1>. Doi: 10.3347/kjp.2003.41.1.1.

FAVERO, J.F.; ARAÚJO, H.L.; LILENBAUM, W.; MACHADO, G.; TONIN, A.A.; BALDISSERA, M.D.; STEFANI, L.M.; SILVA, A.S. Bovine leptospirosis: Prevalence, associated risk factors for infection and their cause-effect relation. Microbial Pathogenesis. $107 \quad$ (2017) 149-154. Disponível em: <http://dx.doi.org/10.1016/j.micpath.2017.03.032>. Doi: 10.1016/j.micpath.2017.03.032.

FERREIRA, S.B.; SOUSA, K.R.S.; CASTRO, V.; LOPES, S.T.P.; FERREIRA, S.B.; FEITOSA, L.C.S.; MOURA, L.M.; MINEIRO, A.L.B.B.; FREITAS, D.R.J.; SOUZA, J.A.T. Análise soroepidemiológica e fatores de risco associados à Leptospira spp. em bovinos no estado do Piauí. Acta Sci Vet [online] 2017; 45: 1494. ISSN 16799216. Disponível em: https://www.researchgate.net.

GIRIO, T.M.S.; MAGAJEVSKI, F.S.; GIRIO, R.J.S.; MIASHYRO, S.; RODRIGUES, L.H.; SCARCELLI, E.P.; TOMA, S.B. Uso de estreptomicina na eliminação da leptospirúria em touros (Bos taurus indicus) naturalmente infectados pelo sorovar Hardjo. Arquivo do Instituto Biológico [online] 2005; 72 (2) 161-170. Disponível em: <http://www.biologico.sp.gov.br/uploads/docs/arq/V72_2/girio.PDF>.

JORGE, S.; SCHUCH, R.A.; OLIVEIRA, N.R.; CUNHA, C.E.P.; GOMES, C.K.; OLIVEIRA, T.L.; RIZZI C.; QDAN, A.F.; PACCE, V.D.; RECUERO, A.L.C.; BROD, C.S.; DELLAGOSTIN, O.A. Human and animal leptospirosis in Southern Brazil: A five-year retrospectivestudy. Travel Medicine and Infectious Disease. 18 (2017) 46-52. Disponível em: <http://www.doi.org/10.1016/j.tmaid.2017.07.010>. Doi: 10.1016/j.tmaid.2017.07.010.

JULIANO, R.S.; CHAVES, N.S.T.; SANTOS, C.A.; RAMOS, L.S.; SANTOS, H.Q.; MEIRELES, R.L.; GOTTSCHALK, S.; FILHO, R.A.C.C. Prevalência e aspectos epidemiológicos da leptospirose bovina em rebanho leiteiro na microrregião de Goiânia - GO. Ciência Rural. Santa Maria, v.30, n.5, p. 857-862, 2000. ISSN 01038478. Disponível em: < http://www.scielo.br/pdf/cr/v30n5/a20v30n5.pdf>.

KLAASEN, H.L.B.M.; ADLER, B. Recent advances in canine leptospirosis: focus on vaccine development. Veterinary Medicine: Research and Reports. 2015:6 245260. Disponível em: <http://dx.doi.org/10.2147/VMRR.S59521. Doi: 10.2147/VMRR.S59521.

LILENBAUM, W.; MARTINS, G. Leptospirosis in Cattle: A Challenging Scenario for the Understanding of the Epidemiology. Transboundary and Emerging Diseases. Suppl. 1 (2014) 63-68. Disponível em: <http://www.doi.org/10.1111/tbed.12233>. Doi:10.1111/tbed.12233.

LOUREIRO, A.P.; MARTINS, G.; THOMÉ, S.; LILENBAUM, W. Laboratorial diagnosis of animal leptospirosis. Revista Brasileira de Ciência Veterinária, v. 20, n. 3, p. 119-126, jul/set 2013. Disponível em: <http://dx.doi.org/10.4322/rbcv.2014.071>. Doi: 10.4322/rbcv.2014.071. 
MARQUES, A.E.; ROCHA, W.V.; BRITO, W.M.E.D.; FIORAVANTI, M.C.S.; PARREIRA, I.M.; JAYME, V.S. Prevalência de anticorpos anti-Leptospira spp. e aspectos epidemiológicos da infecção em bovinos do estado de Goiás. Ciência Animal Brasileira, v. 11, n. 3, p. 607-617, 2010. Disponível em: <http://dx.doi.org/10.5216/cab.v11i3.5460>. Doi: 10.5216/cab.v11i3.5460.

MENEGAS, P.H.; TONETTE, G.; OLIVEIRA, L.A.; FREITAS, J.C.; GONÇALVES, D.D. Leptospirose em propriedade rural com histórico de aborto bovino da região centro-sul do estado do paraná - relato de caso. Enciclopédia Biosfera , Centro Científico Conhecer - Goiânia, 2013, v.9, n.17; p. 1783. Disponível em: $<$ http://www.conhecer.org.br/enciclop/2013b/CIENCIAS

$\% 20 A G R A R I A S / l e p t o s p i r o s e . p d f>$.

MINEIRO, A.L.B.B.; BEZERRA, E.E.A.; VASCONCELLOS, S.A.; COSTA, F.A.L.; MACEDO, N.A. Infecção por Leptospira em bovinos e sua associação com transtornos reprodutivos e condições climáticas. Arquivo Brasileiro de Medicina Veterinária e Zootecnia. Zootec., v.59, n.5, p.1103-1109, 2007. Disponível em: < http://dx.doi.org/10.1590/S0102-09352007000500003>. Doi: 10.1590/S010209352007000500003.

MUYLKENS, B.; THIRY, J.; KIRTEN, P.; SCHYNTS, F.; THIRY, E. Bovine herpesvirus 1 infection and infectious bovine rhinotracheitis. Veterinary Research. 38 (2007) 181-209. Disponível em: <http://dx.doi.org/10.1051/vetres:2006059>. Doi: 10.1051/vetres:2006059.

NILNONT, T.; AIUMLAMAI, S.; KANISTANONT, K.; INCHAISRI, C.; KAMPA, J. Bovine viral diarrhea virus (BVDV) infection in dairy cattle herds in northeast Thailand. Tropical Animal Health and Production (2016). Volume 48, Issue 6, pp 1201-1208. Disponível em: <https://doi.org/10.1007/s11250-016-1075-9>. Doi: 10.1007/s11250-016-1075-9.

OGAWA, L.; FREIRE, R.L.; VIDOTTO, O.; GONDIM, L.F.P.; NAVARRO, I.T. Occurrence of antibodies to Neospora caninum and Toxoplasma gondii in dairy cattle from the northern region of the Paraná State, Brazil. Arquivo Brasileiro de Medicina Veterinária e Zootecnia.vol.57 no.3 Belo Horizonte, Jun. 2005. Disponível em: <http://dx.doi.org/10.1590/S0102-09352005000300006>. Doi: 10.1590/S010209352005000300006.

OLIVEIRA, S.V.; ARSKY, M.L.N.S.; CALDAS, E.P. Reservatórios animais da leptospirose: Uma revisão bibliográfica. Saúde (Santa Maria), v.39, n.1, p. 920, 2013. ISSN 22365834. Disponível em: < https://periodicos.ufsm.br/revistasaude/article/viewFile/5094/pdf_1>.

PAIXÃO, A.P.; SANTOS, H.P.; ALVES, L.M.C.; PEREIRA, H.M.; CARVALHO, R.F.B.; FILHO, V.M.C.; OLIVEIRA, E.A.A.; SOARES, D.M.; BESERRA, P.A. Leptospira spp. em bovinos leiteiros do estado do Maranhão, Brasil: frequência, fatores de risco e mapeamento de rebanhos reagentes. Arquivos do Instituto Biológico, v.83, 1-12, e1022014, 2016. Disponível em: 
<http://www.doi.org/10.1590/1808-1657001022014>. Doi: 10.1590/18081657001022014.

PAL M.; GIZAW, F.; FEKADU, G.; ALEMAYEHU, G.; KANDI, V. Public health and economic importance of bovine brucellosis: an overview. American Journal of Epidemiology and Infectious Disease, 2017, Vol. 5, No. 2, 27-34. Disponível em: <http://www.doi.org/10.12691/ajeid-5-2-2>. Doi: 10.12691/ajeid-5-2-2.

PARTHIBAN, S.; MALMARUGAN, S.; MURUGAN, M.S.; JOHNSON RAJESWAR, J.; POTHIAPPAN, P. Review on emerging and reemerging microbial causes in bovine abortion. International Journal of Food Sciences and Nutrition. 2015, 4(4-1): 1-6. Disponível em: http://dx.doi.org/10.11648/j.jjnfs.s.2015040401.11>.Doi:10.11648/j.ijnfs.s.201504040 $1.11>$.

SANTOS, T.R.; COSTA, A.J.; TONIOLLO, G.H.; LUVIZOTTO, M.C.R.; BENETTI, A.H.; SANTOS, R.R.; MATTA, D.H.; LOPES, W.D.Z.; OLIVEIRA, J.A.; OLIVEIRA, G.P. Prevalence of anti-Toxoplasma gondii antibodies in dairy cattle, dogs, and humans from the Jauru micro-region, Mato Grosso state, Brazil. Veterinary Parasitology. Vol. 161, Issues 3-4, 12 May 2009, Pages 324-326. Disponível em: <http://dx.doi.org/10.1016/j.vetpar.2009.01.017>. Doi: 10.1016/j.vetpar.2009.01.017.

SILVA, J.B.; CASTRO, G.N.S.; SANTOS, P.N.; FONSECA, A.H.; LIMA, D.H.S.; BOMJARDIM, H.A.; REIS, A.S.B.; SOARES, S.O.; BARBOSA, J.D. Detection of a high prevalence of antibodies against Toxoplasma gondii in cattle in Northern and Midwestern Brazil. Revista de Salud Animal. Vol. 37 No. 1 (jan-abr.) 2015: 52-56. ISSN: 2224-4700. Disponível em: https://www.researchgate.net.

WORLD HEALTH ORGANIZATION. Current problems in Leptospirosis Research. Geneva, 1967.

YADETA, W.; BASHAHUN, M. G.; ABDELA, N. Leptospirosis in Animal and its Public Health Implications: A Review. World Applied Sciences Journal, 34 (6): 845-853, 2016. Disponível em: <http://dx.doi.org/10.5829/idosi.wasj.2016.34.6.103113>. Doi: 10.5829/idosi.wasj.2016.34.6.103113. ISSN 1818-4952. 